darkness of the caves where millions congregate to breed. Harrisson remarks that Governments "by some complicated zoo-geology, claim the guano as a mineral and allow extraction (for fertilizer) under licence. Thus what comes out of the swiftlets' mouth as spit is succinctly dissociated from what comes out of the other end". The chapters by Dr. Freeman cover Iban augury, "the interpretation of divine revelation as it is believed to be manifested in the behaviour of certain sacred birds", and the hornbill ritual of the Iban of Sarawak. The first part of the book is illustrated with 19 plates, two of them in colour.

The publishers are to be congratulated on the excellent standard of production, worthy of this valuable addition to ornithological literature.

L. HaRRISON MatThews

\section{VEGETATION AND FOREST TREES OF GHANA}

Synecology and Silviculture in Ghana

By Dr. Charles J. Taylor. Pp. xi $+418+120$ plates. (Edinburgh and London: Thomas Nelson and Sons, Ltd., 1960. Published on behalf of The University College of Ghana.) 100s. net.

T $\mathrm{HE}$ title of this book is unfortunate, despite its euphony, because to many potential readers it will suggest something penetrating far deeper into ecological phenomena and sylvicultural practice than was ever intended, and so leave them unjustifiably disappointed. The book consists chiefly of descriptions and notes on about 160 economically or ecologically important tree-species of the Ghana rain forest. About half the letterpress devoted to each species describes its visible features; the remainder, its habitat, distribution, phenology, and, where appropriate, its sylvicultural behaviour or treatment, and its seed and seedling. The descriptions are aided by numerous photographs and drawings which doubtless account for the high cost of the book. The line drawings are less finished than many which have been published, but most of them are adequate. It is a pity that some of the drawings of seedlings are the least satisfactory (for example, Guarea cedrata, Pterygota macrocarpa), for it is sometimes impossible to tell from them what shape the cotyledons are, and in particular whether they are thin or fleshy. The photographs form a very useful collection, and represent an amount of work which only those with experience of photography in rain forest will appreciate.

This systematic part, which forms about three. quarters of the whole, is prefaced by a brief outline of the history, topography, soils, climate and vegetation of Ghana, excellent in its way, but somewhat disjointed and with little relevance to what follows. This general matter will be useful-but doubtfully worth £5-to students of geography or botany. Dr. Taylor writes with generally commendable simplicity, though occasionally his language becomes a little too simple for accuracy, and some ecological terms (for example, plagiosere), are used incorrectly.

The style and content of the book show that it is intended for use chiefly in Ghana. Here the book will undoubtedly be an invaluable companion to ecologists and foresters; elsewhere in the West African rain forest it will be useful chiefly for its descriptions of 'slash' and other field characters, and of seedlings. Although it is not a flora, one of its principal uses will undoubtedly be for naming trees, for which it could be greatly improved by $(a)$ referring in the text to the plates, (b) by stressing (for example, by italics) the most useful diagnostic characters, and (c) by adding some kind of key or summary-table which would help the beginner in knowing which family to consult.

The book is well produced and contains very few misprints.

E. W. Jones

\section{THE CONVOLUTION TRANSFORM}

\section{Operational Calculus}

By Prof. Jan Mikusiński. (International Series of Monographs on Pure and Applied Mathematics, Vol. 8.) Pp. 495. (London and New York: Pergamon Press ; Warszawa: Panstwowe Wydawnictwo Naukowe, 1959.) 100s. net.

THERE are many ways of developing the transform calculus, all more or less formally equivalent. Mikusinski's starting point is somewhat uncommon : the convolution of two functions $a(t), b(t)$ is

$$
\int_{0}^{t} a(t-u) b(u) d u
$$

which he writes as $a b$. Since

$$
a b+a c=a(b+c), a b=b a,(a b) c=a(b c)
$$

while $a b$ is not identically zero unless $a(t)$ or $b(t)$ is identically zero (Titchmarsh's theorem), we have an algebraic structure which is similar to Volterra's algebra of composition, and a formulation which is equivalent to Heaviside's 'algebrization' of functional operations. There are some differences, for convolutions exist over the class of continuous functions, whereas the existence of the Laplace transform requires an order condition. There is also an early difficulty, for if $a$ and $b$ are constants, does $a b$ mean their arithmetic product or their convolution abt? Volterra used a special notation $a^{*} b^{*}$, while Mikusiński gets over the ambiguity by distinguishing the functional form $\{f(t)\}$ from the functional value $f(t)$; once one gets used to this, the calculus is simple and effective, though the reader will find it necessary at a later page to pay special attention to the introduction of operational functions.

There are plenty of applications, to electric circuits, statics of beams, vibrations, the heat and cable equations, and a good supply of exercises. Those who know the earlier Polish, Russian or German versions will appreciate the appendix of a hundred pages in the English edition, for this not only carries certain applications further, and provides on the theoretical side a link with Banach spaces, but, even more usefully, adds details to complete certain proofs which are only sketched in the main text. While perhaps the young student should stick to one line, of approach to the operational calculus, his teacher should select such a line for him from a knowledge of alternatives; Mikusiński's book provides a very pleasant account, worth studying for its own sak $\theta$ and for comparison with more familiar formulations of this calculus.

T. A. A. BroadBent 